\title{
Meta-analysis of corpus callosum size in schizophrenia
}

P W R Woodruff, I C McManus, A S David

\begin{abstract}
Studies with MRI have shown differences in corpus callosum size between schizophrenic patients and controls. Most have found that the corpus callosum is smaller in schizophrenic patients, but in only a minority was this finding statistically significant, perhaps due to small sample sizes. Therefore a meta-analysis of 11 published studies of corpus callosum morphology in schizophrenia was conducted to ascertain whether there was a significant difference in corpus callosum size between schizophrenic patients and normal controls. These studies combined comprised 313 patients and 281 controls. Measures of corpus callosum midsagittal area, length, and corpus callosum area:brain area ratio were used in the meta-analysis. There was overall a statistically significant reduction in corpus callosum area in schizophrenic patients compared with controls $(P<0.02)$. Differences between patients and controls in measures of corpus callosum: brain area and corpus callosum length were not statistically significant. Age and corpus callosum area were related in both patients and controls. The influences on the corpus callosum of overall alterations of brain size, sex, handedness, and psychiatric illness in general remains to be determined.
\end{abstract}

$(\mathcal{F}$ Neurol Neurosurg Psychiatry 1995;58:457-461)

Department of

Psychological

Medicine, Institute of

Psychiatry, London,

UK

P W R Woodruff

Department of

Psychiatry, St Mary's

Hospital Medical

School, Imperial

College of Science,

Technology and

Medicine, London, UK

I C McManus

King's College

Hospital and Institute of Psychiatry, London

SE5 8AF

A S David

Correspondence to:

Dr A S David, Institute of

Psychiatry, De Crespigny

Park, Denmark Hill, London SE5 8AF, UK.

Received 16 May 1994 and in final revised form 22 October 1994

Accepted 5 January 1995
Keywords: meta-analysis; corpus callosum size; schizophrenia

The corpus callosum was proposed as the seat of insanity as long ago as 1844 when Wigan published his treatise. ${ }^{1}$ Psychiatric interest in the structure began in earnest after a postmortem study that compared the callosal width of 10 cases of chronic schizophrenia with 10 age matched subjects and found a $1 \mathrm{~mm}$ increase in thickness in the schizophrenic group. ${ }^{2}$ This interest has waxed and waned ever since. ${ }^{34} \mathrm{~A}$ further study by the same group showed that this pattern was not seen in schizophrenic patients as a whole but only in a subgroup of cases with early onset. ${ }^{5}$ Few other postmortem studies have concentrated on the corpus callosum, and when mentioned it is often said to be normal. ${ }^{6}$ Interpretation of postmortem studies is complicated by small sample size, different causes of death in cases and controls, and postmortem changes such as swelling induced by fixation and staining. ${ }^{7}$

The widespread application of MRI from the mid-1980s has allowed the direct visualisation of the corpus callosum in vivo. Magnetic resonance imaging has shown cases of dysgenesis presenting with schizophrenia, ${ }^{8-10}$ the existence of which supports those who proposed neurodevelopmental theories of schizophrenia. ${ }^{11}$ The main use of MRI, however, has been to allow quantitative measurement of the corpus callosum in larger numbers of cases than those reaching postmortem and without many of the associated artefacts. Despite this, there has so far been little consensus as to whether the corpus callosum is abnormal in schizophrenia. Early reports suggested increased width in female cases, ${ }^{12}$ whereas other reports claimed reductions in size in comparison with normal controls. ${ }^{13-15}$ Raine $e t ~ a l,{ }^{16}$ in one of the few studies to have included a psychiatric comparison group, showed increased anterior callosal width in female psychotic patients.

Accurate and reliable measurement of the corpus callosum poses challenges. The corpus callosum is readily identifiable on coronal and sagittal views with MRI, with most researchers preferring the midsagittal corpus callosum area as their main dependent variable (Young et $a l^{17}$ used coronal views). Considerable variation will be introduced if the slice taken is parasagittal and the angle of slice is oblique. Also, there is wide normal variation in the shape and curvature of the corpus callosum increasing the likelihood that comparisons of small groups of subjects will yield spurious differences or, alternatively, overlook true differences. This variation may account for the continued controversy as to whether there are sex and handedness differences in the corpora callosa of normal subjects. ${ }^{18-21}$ When the biases complicating the selection of cases for biological research in psychiatry-such as severity of illness, and potential confounders linking schizophrenia and brain dimensions, such as low IQ, substance abuse, brain injury, and treatment-are added, it is hardly surprising that the studies to date have been inconclusive. Finally, research looking at specific parts of the corpus callosum, such as the "anterior third", or other measures such as "maximum width", although theoretically justified, has the added difficulty of defining regions of interest with adequate reliability.

For these reasons we have carried out a 
meta-analysis of published data on corpus callosum area in schizophrenia. This technique confers greater statistical power than can be achieved by a single research group, and is able to make use of data from small studies on diverse groups. The hypothesis under test was simply that the corpus callosum is abnormal in schizophrenia. In addition, meta-analysis can often shed light on the critical reasons for conflicting reports in the medical literature such as those due to differing methods and subject characteristics.

\section{Methods}

Using computerised and manual literature searches (Medline, PsychLit, and Index Medicus), 17 MRI studies on schizophrenic patients between the years 1984-93 were identified in which the corpus callosum had been measured. ${ }^{12-1722-32}$ Studies were included if sufficient data were reported including the mean and SD of midsagittal corpus callosum measures in SI units. Excluded were the study by Casanova et $a l^{2}$ because measurements were only quoted in non-standardised pixel units, precluding comparison with other studies, and that of Young et al, ${ }^{17}$ which measured corpus callosum coronal height only. Also excluded were studies by Smith and colleagues ${ }^{23} 2426$ as only ratios of corpus callosum area to other brain measurements are given. Where preliminary studies had apparently been performed on similar patient groups, only the definitive study in which findings were reported on the larger group was included. Hence, Stratta et $a l^{14}$ superseded Stratta et $a l^{25}$ leaving 11 studies remaining for analysis. ${ }^{12-162328-32}$ From these, information was extracted pertaining to three groups of factors: "dependent" variables, "study quality" variables, and "predictors of differences" between schizophrenic patients and controls (table 1). Dependent variables included midsagittal measures of corpus callosum area $\left(\mathrm{cm}^{2}\right)$, brain area $\left(\mathrm{cm}^{2}\right)$, and corpus callosum length $(\mathrm{cm})$. Scan variables were treated as indicators of scan quality-namely, power of magnet used for MRI (Tesla value), slice thickness (greater weighting to thinner slices). The variable "study quality" was computed for each study, calculated as the number of a range of descriptive measures that were reported in the paper in addition to scan quality-namely (a) matching of groups by paternal social class, (b) matching of groups by handedness, $(c)$ measured reliability of technique, (d) use of computerised outlining method, and mention of $(e)$ patient exclusion criteria, $(f)$ patient years of education, $(g)$ age (SD) of onset of schizophrenia, $(h)$ duration (SD) of schizophrenia, (i) clinical details of patients, $(\mathcal{J})$ number of hospital admissions, $(k)$ age $(\mathrm{SD})$ of patients, $(l)$ number of male patients.

To determine if overall there was a significant difference in corpus callosum measures between schizophrenic patients and controls, the mean effect size using the control subjects as covariate was calculated. This was done with Hedges $g$; formula:

$$
g=\left(M_{1}-M_{2}\right) / s
$$

where $M_{1}$ and $M_{2}$ represent the means in patients and controls, and $s$ is the pooled SD. This formula takes account of the number of subjects in each study and the differences in SD between cases and controls. ${ }^{33}$

\section{Results}

Table 2 shows unweighted descriptive statistics across the studies used in the analysis. The figure illustrates the mean corpus

Table 1 Studies of corpus callosum area in schizophrenia

\begin{tabular}{|c|c|c|c|c|c|c|c|c|c|c|c|c|c|c|}
\hline \multirow[b]{3}{*}{ Study (ref) } & \multicolumn{6}{|c|}{ Schizophrenic patients } & \multicolumn{4}{|c|}{ Controls } & \multirow{2}{*}{\multicolumn{2}{|c|}{$\begin{array}{l}\text { Corpus callosum area } \\
\left(\mathrm{cm}^{2}\right)(\text { mean }(S D))\end{array}$}} & \multirow[b]{3}{*}{ Method } & \multirow{3}{*}{$\begin{array}{l}\text { Study } \\
\text { quality } \\
\text { score } \\
(1-19)\end{array}$} \\
\hline & \multirow{2}{*}{$\begin{array}{l}\text { Subject } \\
\text { type }\end{array}$} & \multirow[b]{2}{*}{ No } & \multirow{2}{*}{$\begin{array}{l}\text { Age }(y) \\
(\text { mean } \\
(S D))\end{array}$} & \multirow{2}{*}{$\begin{array}{l}\% \\
\text { Male }\end{array}$} & \multirow{2}{*}{$\begin{array}{l}\text { Illness } \\
\text { duration } \\
\text { (SD) }\end{array}$} & \multirow{2}{*}{$\begin{array}{l}\text { Age of } \\
\text { onset } \\
\text { (SD) }\end{array}$} & \multirow[b]{2}{*}{ No } & \multirow{2}{*}{$\begin{array}{l}\text { Subject } \\
\text { type }\end{array}$} & \multirow{2}{*}{$\begin{array}{l}\text { Age (y) } \\
\text { (mean } \\
(S D))\end{array}$} & \multirow{2}{*}{$\begin{array}{l}\% \\
\text { Male }\end{array}$} & & & & \\
\hline & & & & & & & & & & & Patients & Controls & & \\
\hline$\underset{1985^{27}}{\text { Matthew }}$ et al & DSM-3 & 18 & $38 \cdot 4(14)$ & $61 \cdot 1$ & $12 \cdot 6(8 \cdot 3)$ & - & 18 & Staff & $38 \cdot 6(13)$ & $55 \cdot 6$ & $1 \cdot 48(0 \cdot 23)$ & $1 \cdot 41(0 \cdot 21)$ & - & 11 \\
\hline$\underset{1986^{12}}{\text { Nasrallah }}$ et al & $\begin{array}{l}\text { DSM-3 } \\
\text { Chronic } \\
\text { relapsed } \\
\text { and } \\
\text { outpatients }\end{array}$ & 38 & $33 \cdot 2(8 \cdot 2)$ & $73 \cdot 7$ & - & $22(4 \cdot 2)$ & 41 & Staff & $28(4 \cdot 9)$ & $51 \cdot 2$ & $6.82(0.97)$ & $6.37(0.99)$ & $\mathbf{P}$ & 11 \\
\hline $\begin{array}{c}\text { Kelsoe et al } \\
1988^{28}\end{array}$ & $\begin{array}{l}\text { DSM-3 } \\
\text { Relapsed }\end{array}$ & 27 & $29(1 \cdot 0)$ & $81 \cdot 5$ & $8.4(0.8)$ & $21(0 \cdot 7)$ & 14 & Staff & $31(1 \cdot 0)$ & $71 \cdot 4$ & $8 \cdot 1(0 \cdot 5)$ & $8.9(0.9)$ & $P$ & 16 \\
\hline $\begin{array}{c}\text { Rossi et al } \\
1988^{13}\end{array}$ & $\begin{array}{l}\text { DSM-3 } \\
\text { Outpatients }\end{array}$ & 15 & $32 \cdot 6$ (?) & 100 & $8 \cdot 0(?)$ & - & 15 & $\begin{array}{l}\text { Staff and } \\
\text { relatives }\end{array}$ & - & 100 & $6 \cdot 26(1 \cdot 35)$ & $6.58(1.99)$ & C & 11 \\
\hline $\begin{array}{l}\text { Uematsu and } \\
\text { Kaiya } 1988^{29}\end{array}$ & DSM-3 & 40 & $32 \cdot 2(6 \cdot 7)$ & 100 & - & - & 17 & $\begin{array}{l}\text { Volun- } \\
\text { teers }\end{array}$ & $31 \cdot 5(5 \cdot 5)$ & 100 & $7 \cdot 46(1 \cdot 05)$ & $7 \cdot 18(0 \cdot 75)$ & $P$ & 12 \\
\hline $\begin{array}{l}\text { Hauser et al } \\
\quad 1989^{30}\end{array}$ & $\begin{array}{l}\text { RDC/ } \\
\text { DSM-3 } \\
\text { Familial }\end{array}$ & 24 & $33 \cdot 0(5 \cdot 3)$ & $45 \cdot 8$ & - & - & 25 & $\begin{array}{l}\text { Staff/ } \\
\text { com- } \\
\text { munity }\end{array}$ & $37 \cdot 0(8 \cdot 6)$ & $56 \cdot 0$ & $5 \cdot 5(1 \cdot 0)$ & $5 \cdot 6(0 \cdot 8)$ & $\mathbf{P}$ & 8 \\
\hline $\begin{array}{c}\text { Raine et al } \\
1990^{16}\end{array}$ & $\begin{array}{l}\text { DSM-3-R } \\
\text { Acute/chroni }\end{array}$ & $c^{15}$ & $33 \cdot 6(12 \cdot 2)$ & $60 \cdot 0$ & $8 \cdot 0(7 \cdot 6)$ & $26 \cdot 1(10 \cdot 0)$ & 18 & Staff & $34 \cdot 1(11 \cdot 3)$ & $50 \cdot 0$ & $5.74(0.80)$ & $5 \cdot 80(1 \cdot 0)$ & C & 17 \\
\hline $\begin{array}{l}\text { Rossi et al } \\
1989^{31}\end{array}$ & $\begin{array}{l}\text { DSM-3 } \\
\text { Chronic }\end{array}$ & 12 & $31 \cdot 5(6 \cdot 3)$ & $66 \cdot 7$ & $7.91(3.94)$ & - & 12 & $\begin{array}{l}\text { Staff and } \\
\text { relatives }\end{array}$ & $30 \cdot 66(6.38)$ & $66 \cdot 7$ & $6 \cdot 15(1 \cdot 04)$ & $7 \cdot 22(1 \cdot 18)$ & C & 14 \\
\hline $\begin{array}{c}\text { Stratta et al } \\
1989^{14}\end{array}$ & DSM-3 & 20 & $33.2(6.52)$ & $75 \cdot 0$ & $8 \cdot 23(7 \cdot 2)$ & - & 20 & $\begin{array}{l}\text { Volun- } \\
\text { teers }\end{array}$ & $32 \cdot 35(6 \cdot 26)$ & $75 \cdot 0$ & $6 \cdot 13(1 \cdot 26)$ & $6 \cdot 61(1.75)$ & C & 15 \\
\hline $\begin{array}{l}\text { Günther et al } \\
1991^{32}\end{array}$ & DSM-3 & 31 & $32 \cdot 3(8 \cdot 32)$ & $61 \cdot 3$ & $2 \cdot 52(1 \cdot 46)$ & - & 31 & $\begin{array}{l}\text { Volun- } \\
\text { teers }\end{array}$ & $32.35(8.06)$ & $61 \cdot 3$ & $6.64(0.87)$ & $6.76(0.47)$ & $\mathbf{P}$ & 15 \\
\hline $\begin{array}{l}\text { Woodruff et al } \\
1993^{15}\end{array}$ & $\begin{array}{l}\text { DSM-3-R } \\
\text { Outpatients/ } \\
\text { inpatients }\end{array}$ & 30 & $29 \cdot 96(7 \cdot 24)$ & $76 \cdot 7$ & $11 \cdot 6(6 \cdot 6)$ & $22 \cdot 4(6 \cdot 7)$ & 44 & $\begin{array}{l}\text { Staff } \\
\text { com- } \\
\text { munity }\end{array}$ & - & $77 \cdot 3$ & $6.35(0.73)$ & $6.98(0.99)$ & C & 19 \\
\hline
\end{tabular}

$\mathrm{P}=$ Manual planimetry; $\mathrm{C}=$ computer assisted technique. 
Mean difference ( $95 \%$ CI) between corpus callosum area in normal controls and schizophrenic patients in 11 published studies.

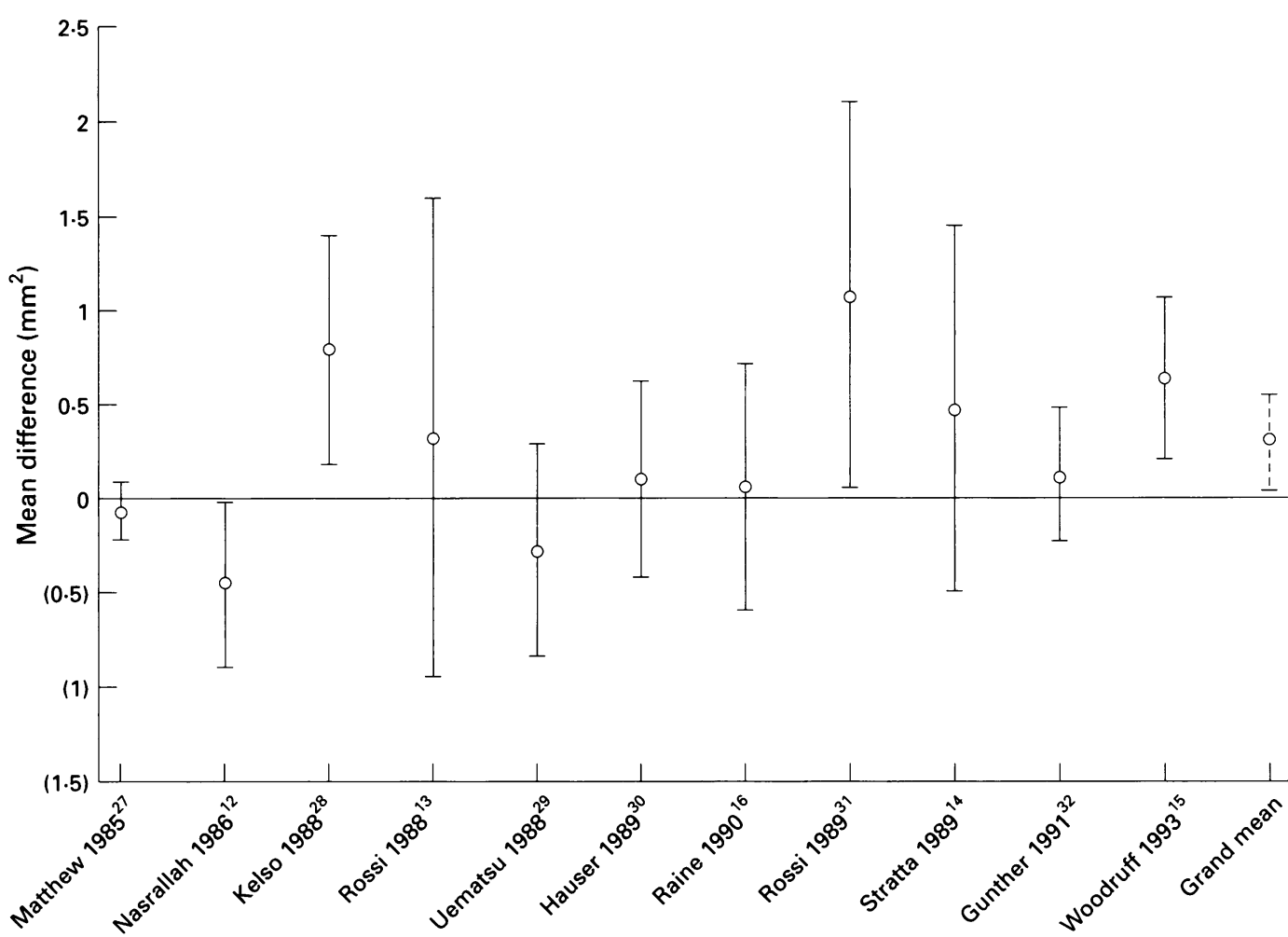

Study-first author, year, and reference number

callosum area plus $95 \%$ confidence intervals (95\% CIs) plotted for schizophrenic patients and controls from each of the studies. In eight of 11 studies that measured corpus callosum area this measure was greater in normal controls than in the schizophrenic patients ( $P=0 \cdot 12$, two tailed, binomial test), particularly so in later studies. For corpus callosum area, the mean effect size was $-0 \cdot 1847$; and the $t$ statistic for the mean effect was 2.3397 $(\mathbf{P}=0 \cdot 019)$. This indicated a statistically significant reduction in corpus callosum area for schizophrenic patients compared with controls across all studies that measured corpus callosum area. Effect sizes of corpus callosum area by diagnosis were negative (corpus callosum is smaller in schizophrenic patients) in eight studies and positive in three. Calculation of effect size for corpus callosum:brain area ratio measured in 10 studies and corpus callosum length in eight studies combined did not show significant differences between patients and controls.

Table 2 Descriptive and mean corpus callosum measures of subjects in published studies

\begin{tabular}{|c|c|c|c|c|}
\hline \multirow[b]{2}{*}{ Descriptives } & \multicolumn{2}{|c|}{ Schizophrenic patients } & \multicolumn{2}{|l|}{ Controls } \\
\hline & Mean (SD) & $\begin{array}{l}\text { Number of } \\
\text { studies }\end{array}$ & Mean (SD) & $\begin{array}{l}\text { Numer of } \\
\text { studies }\end{array}$ \\
\hline Age & $32.08(2.65)$ & 13 & $33.26(3.36)$ & 11 \\
\hline$\%$ Male & $68.04(23 \cdot 11)$ & 12 & $68.25(18.08)$ & 13 \\
\hline Years of education & $12.51(0.55)$ & 4 & $15.07(2.79)$ & 2 \\
\hline Duration of illness ( $y$ ) & $8 \cdot 21(2 \cdot 87)$ & 9 & & \\
\hline Age of onset $(y)$ & $22 \cdot 87(2 \cdot 23)$ & 4 & & \\
\hline Corpus callosum: & & & & \\
\hline $\begin{array}{l}\text { Area }\left(\mathrm{cm}^{2}\right) \\
\text { Length }(\mathrm{cm})\end{array}$ & $\begin{array}{l}6.06(1.69) \\
6.90(1.43)\end{array}$ & $\begin{array}{r}11 \\
8\end{array}$ & $\begin{array}{l}6.31(1.84) \\
6.83(1.51)\end{array}$ & $\begin{array}{r}11 \\
8\end{array}$ \\
\hline
\end{tabular}

${ }^{\star}$ Total number of schizophrenic patients $=313$; ftotal number of control patients $=281$. $\mathrm{SD}$ refers to variance in age across the studies.
Weighted multiple regression analyses were used to predict effect size in relation to nine independent variables, the method of weighting following that recommended by Hedges and Olkin. ${ }^{34}$ Forward entry was used with a studywise significance level of 0.05 , calculated with a Bonferroni correction as a nominal significance level of $0 \cdot 05 / 9=0 \cdot 0055$. Independent variables were year of study, number of subjects, age, SD age, Tesla of magnet used, slice thickness, method (planimetry or computer assisted outlining method), sex, and "study quality". The dependent variables in three separate analyses were corpus callosum area of schizophrenic patients; corpus callosum area of controls; and corpus callosum area in schizophrenic patients after entering corpus callosum area of controls as a covariate; the last analysis in effect assesses the difference in area between schizophrenic patients and controls. The difference in corpus callosum area between the two groups takes into account sample size and the number of subjects may also be included as a quality variable (smaller studies may be more susceptible to selection bias) without invalidating the analyses.

There was an association between greater age of subjects and smaller corpus callosum area. The main predictor of overall corpus callosum area was age of subjects in both controls (nominal significance $=0.0057$ ) and in schizophrenic patients $(p=0.004)$, and in schizophrenic patients relative to controls ( $p$ $=0.0004)$. Much of the effect of age on corpus callosum area seemed to be contributed by the study of Matthew et al, ${ }^{27}$ in which the mean age was greater and corpus callosum smaller than most studies. If this study was 
excluded from the analysis there was no longer a significant effect of age on corpus callosum area overall, but the difference between schizophrenic patients and controls remained. Although the five studies that employed a computer assisted measurement technique rather than manual planimetry all found corpus callosum area less in schizophrenic patients than in controls, a significant effect of the method of measurement was not found.

\section{Discussion}

The meta-analysis showed a significant reduction of corpus callosum area in schizophrenic patients compared with controls across 11 studies analysed. There was no significant difference between schizophrenic patients and controls in corpus callosum area:brain area or corpus callosum length, but fewer studies measured these variables. Furthermore, the use of ratios as a means of controlling for brain size has been criticised on methodological grounds. ${ }^{35}$ The alternative methodnamely, analysis of covariance (ANCOVA) to control for brain size showed significantly reduced corpus callosum area in schizophrenic patients. ${ }^{15}$

Age may influence corpus callosum size. Normally, myelination continues well into adulthood and so corpus callosum size may be expected to increase initially with time, declining as the subject ages. The relation in schizophrenia between corpus callosum size and age, however, is less clear. One study reported a positive correlation with age, ${ }^{15}$ whereas another found no such relation. ${ }^{25}$ Excluding the study by Matthew et al ${ }^{27}$ eliminated the effect of age on corpus callosum area from the meta-analysis. It would seem, therefore, that the age effect is not robust, and is principally due to the study of Matthew et $a l^{27}$ being an outlier.

The influential study of Nasrallah et $a l^{12}$ found no difference in corpus callosum widths between male schizophrenic patients and controls. This finding differs from MRI studies that found differences, predominantly in males. ${ }^{15}$ The increased corpus callosum width in schizophrenic patients found by Nasrallah et $a l^{12}$ was due to the comparison of female schizophrenic patients with female controls. This is contrary to the findings of Hauser $e t a^{30}$ in females, but is in line with the work of Raine et $a l,{ }^{16}$ who found that female schizophrenic patients and other psychiatric patients had larger corpus callosum areas than normal controls, but the pattern was reversed in males. Because few of the studies employed a psychiatric control group, our meta-analysis was confined to schizophrenic $v$ normal subjects. Future work should consider the issue of reduced corpus callosum area in psychiatric conditions to ascertain its specificity to schizophrenia.

There are methodological problems associated with the use of linear measures of width of the corpus callosum in view of its varied shape. ${ }^{22}$ Results differ considerably depending on whether widths are determined from lines drawn vertically or perpendicularly to the corpus callosum surface. ${ }^{15}$ Therefore, early findings based on width measures should be interpreted with caution. Furthermore, it may be that altered size of constituent parts of the corpus callosum are important in schizophrenia. The isthmus contains fibres that connect both superior temporal gyri. Reduced superior temporal gyrus volume has been associated with the tendency to develop auditory hallucinations. ${ }^{36}$ Woodruff et $a l^{15}$ reported that reduced isthmus area was especially pronounced in schizophrenic patients. Raine et $a l,{ }^{16}$ on the other hand, noted particular reduction of the anterior portion of the corpus callosum. In a study that only measured the anterior corpus callosum (and did not therefore satisfy the criteria for inclusion in the meta-analysis), reduction of this region was associated with auditory hallucinations, ${ }^{37}$ although Günther et $a l^{32}$ found that schizophrenic patients with increased corpus callosum area had a predominance of positive symptoms whereas those with reduced areas had more negative symptoms. Woodruff et al ${ }^{15}$ found an inverse correlation between corpus callosum size and delusions. Further studies with adequate statistical power are needed to clarify the structural and functional relations of the corpus callosum. For example, are identifiable subtypes of schizophrenic patients liable to abnormalities of the corpus callosum dimensions?

Another avenue for further research is to look for clues as to the timing and mechanisms for processes underlying corpus callosum abnormalities. The fact that overall area reduction but not length difference was detected in schizophrenia leads to the conclusion that schizophrenic corpora callosa are thinner but not shorter. This may have implications for determining the pathological processes involved-for example, dystrophy $v$ degeneration-and their timing in development. Is, for instance, corpus callosum size reduction in schizophrenia related to that of medial temporal lobe structures? The lack of difference between groups in the corpus callosum:brain ratio further suggests that corpus callosum dimensions should not be measured in isolation. We were unable to exclude the possibility that the reduced corpus callosal area in this meta-analysis is merely an index of the well established generalised reduction in cerebral volume in schizophrenia, ${ }^{38} 39$ or an increase in ventricle:brain ratio, ${ }^{40}$ although in one study that controlled for brain size, corpus callosum area in schizophrenic patients remained significantly less than controls. ${ }^{15}$

In conclusion, meta-analysis of 11 studies has shown an overall difference in corpus callosum size in schizophrenia. Studies with samples with mixtures of sex and handedness may have been too small alone to detect significant differences but when put together a more consistent pattern has emerged. This will hopefully help us explore further the clinicopathological relevance of corpus callosum abnormalities in schizophrenia. 
1 Clarke B. Arthur Wigan and the duality of mind. Psychol Med Monogr suppl 1987;11.

2 Rosenthal R, Bigelow LB. Quantitative brain measurements in chronic schizophrenia. Br $\mathcal{F}$ Psychiatry 1972; 121:259-64.

3 Coger RW, Serafetinides EA. Schizophrenia, corpus callosum, and interhemispheric communication: a review. Psychiatry Res 1990;34:163-84.

4 David AS, Schizophrenia and the corpus callosum developmental, structural, and functional relationships. Behav Brain Res 1994;64:203-11.

5 Bigelow LB, Nasrallah HA, Rauscher FP. Corpus callosum thickness in chronic schizophrenia. $\mathrm{Br} \mathcal{F}$ Psychiatry 1983;142:284-7.

6 Brown R, Colter N, Corsellis JAN, et al. Postmortem evidence of structural brain changes in schizophrenia. Arch Gen Psychiatry 1986;43:36-42.

7 Bogerts B. Recent advances in the neuropathology of schizophrenia. Schizophr Bull 1993;19:431-445.

8 David AS, Wacharasindhu A, Lishman WA. Developmental abnormalities of the corpus callosum and severe psychiatric disorders: review and case series. $f$ Neurol Neurosurg Psychiatry 1994;56:85-93.

9 Degreef G, Lantons G, Bogerts B, Ashtari M, Lieberman J. Abnormalities of the septum pellucidum on MR scans in first-episode schizophrenic patients. $A \mathcal{F N R} A m \mathfrak{F}$ Neuroradiol 1992;13:835-840.

10 Filteau M-J, Pourcher E, Bouchard RH, et al. Corpus callosum agenesis and psychosis in Andermann syndrome. Arch Neurol 1991;48:1275-80.

11 Jones P, Murray RM. The genetics of schizophrenia is the genetics of neurodevelopment. Br F Psychiatry 1989;158: 615-23.

12 Nasrallah HA, Andreasen NC, Coffman JA, et al. A controlled magnetic resonance imaging study of corpus
callosum thickness in schizophrenia. Biol Psychiatry callosum thickness

13 Rossi A, Stratta P, Gallucci M, Passariello R, Casacchia $M$. Brain morphology in schizophrenia by magnetic resonance imaging. Acta Psychiatrica Scandinavica 1988; 77:741-5

14 Stratta P, Rossi A, Gallucci M, et al. Hemispheric asymmetries and schizophrenia: a preliminary magnetic resonance imaging study. Biol Psychiatry 1989;25: 275-84.

15 Woodruff PWR, Pearlson GD, Geer MJ, Chilcoat HD. A computerized magnetic resonance imaging of corpus callosum morphology in schizophrenia. Psychol Med 1993;23:45-56.

16 Raine A, Harrison GN, Reynolds GP, Sheard C, Cooper JE, Medley I. Structural and functional characteristics of the corpus callosum in schizophrenics, psychiatric controls, and normal controls. Arch Gen Psychiatry 1990; 47:1060-3.

17 Young AH, Blackwood DHR, Roxborough H, McQueen JK, Martin MJ, Kean D. A magnetic resonance imaging study of schizophrenia: brain structure and clinical symptoms. Br $\mathcal{F}$ Psychiatry 1991;158:158-64

18 Witelson SF. Hand and sex differences in the isthmus and genu of the human corpus callosum. Brain 1989;112 799-835.

19 Clarke S, Kraftsik R, Van der Loos H, Innocenti GM. Forms and measures of adult and developing human corpus callosum: Is there sexual dimorphism? $f$ Comp Neurol 1989;280:213-30.

20 Habib M, Gayraud D, Oliva A, Regis J, Salamon G, Khalil R. Effects of handedness and sex on the morphology of the corpus callosum: a study with brain magnetic resonance imaging. Brain Cogn 1991;16:41-61.
21 Wahlsten D, Bishop KM. Sex differences in the human corpus callosum - myth or reality? 1994 (in press).

22 Casanova MF, Sanders RD, Goldberg TE, et al. Morphometry of the corpus callosum in monozygotic wins discordant for schizophrenia: a magnetic resonance imaging study. $\mathcal{F}$ Neurol Neurosurg Psychiatry 1990 53:416-421.

23 Smith RC, Baumgartner R, Calderon M. Magnetic resonance imaging studies of the brains of schizophrenic patients. Psychiatry Res 1987;20:33-46.

24 Smith R, Tamminga CA. Brain imaging in psychiatry: new developments. Psychopharmacol Bull 1985;21:588-94.

25 Stratta P, Casacchia M, Amicarelli I, Gallucci M, Rossi A, Passariello R. Midsagittal cortical pathomorphology of schizophrenia: a magnetic resonance imaging study. Psychiatry Res 1989;25:275-84.

26 Smith RC, Calderon M, Ravichandran GK, et al. Nuclear magnetic resonance in schizophrenia: a preliminary magnetic resonance in schizophre
study. Psychiatry Res 1984;12:137-47.

27 Matthew RJ, Partain CL Prakash R, Kulkarni MV, Logan TP, Wilson WH. A study of the septum pellucidum and corpus callosum in schizophrenia. Acta Psychiatrica Scandinavica 1985;72:414-21.

28 Kelsoe JR, Cadet JL, Pickar D, Weinberger DR Quantitative neuroanatomy in schizophrenia. Arch Gen Psychiatry 1988;45:533-41.

29 Uematsu M, Kaiya H. The morphology of the corpus callosum in schizophrenia: an MRI study. Schizophr Res 1988;1:391-8.

30 Hauser P, Dauphinais D, Berrettini W, DeLisi LE, Gelernter J, Post RM. Corpus callosum dimensions measured by magnetic resonance imaging in bipolar affective disorder and schizophrenia. Biol Psychiatry 1989;26:659-68.

31 Rossi A, Stratta P, Gallucci M, Passariello R, Casacchia $M$. Quantification of corpus callosum and ventricles in schizophrenia with nuclear magnetic resonance imaging: schizophrenia with nuclear magnetic resonance

32 Günther W, Petsch R, Steinberg R, et al. Brain dysfunction during motor activation and corpus callosum alterations in schizophrenia measured by cerebral blood flow and magnetic resonance imaging. Biol Psychiatry 1991;29:535-55.

33 Rosenthal R. Meta-analytical procedures for social research. London: Sage Publications, 1984.

34 Hedges LV, Olkin L. Regression models in research synthesis. American Statistician 1983;37:137-40.

35 Arndt S, Cohen G, Alliger RJ, Swayze VW, Andreasen NC. Problems with ratio and proportion measures of imaged cerebral structures. f Psychiatr Res 1991;40: imaged

36 Barta PE, Pearlson GD, Powers RE, Richards SS, Tune LE. Auditory hallucinations and smaller superior temporal gyral volume in schizophrenia. Am f Psychiatry 1990;147:1457-62.

37 David AS, Minne C, Jones P, Harvey I, Ron MA. Structure and function of the corpus callosum in schizophrenia: what's the connection? European Psychiatry 1995 (in press).

38 Zipursky RB, Lim KO, Sullivan EV. Widespread cerebra rey matter volume in schizophrenia. Arch Gen Psychiatry 1992;49:195-205.

39 Harvey I, Ron MA, DuBoulay G, Wicks D, Lewis SW, Murray RM. Reduction of cortical volume in schizophrenia on magnetic resonance imaging. Psychol Med phrenia on magne

40 Van Horn J, McManus IC. Ventricular enlargement in schizophrenia: a meta-analysis of studies of the ventriclebrain ratio. Br $\mathcal{F}$ Psychiatry 1992;160:687-97. 